\title{
CDGSH Iron-Sulfur Domain-Containing Protein 2
}

National Cancer Institute

\section{Source}

National Cancer Institute. CD GSH Iron-Sulfur Domain-Containing Protein 2. NCI

Thesaurus. Code C116301.

CDGSH iron-sulfur domain-containing protein 2 (135 aa, $\sim 15 \mathrm{kDa}$ ) is encoded by the human CISD2 gene. This protein plays a role in the regulation of autophagy. 